\title{
Carbohydrate Metabolism in Rhizobium trifolii: Identification and Symbiotic Properties of Mutants
}

\author{
By CLIVE W. RONSON* AND SANDY B. PRIMROSE \\ Department of Biological Sciences, University of Warwick, Coventry CV4 $7 \mathrm{AL}$
}

(Received 7 September; revised 13 November 1978)

Crude extracts of Rhizobium trifolii strain 7000 contained enzymes of the Entner-Doudoroff and pentose phosphate pathways. No phosphofructokinase (EC 2.7.1.11) activity and only a low activity of fructose-1,6-bisphosphate aldolase (EC 4.1.2.13) were found, suggesting that the Embden-Meyerhof-Parnas pathway was not physiologically important in this strain.

Independent carbohydrate-negative mutants of $R$. trifolii were isolated and characterized as deficient in glucokinase ( $g l k ;$ EC 2.7.1.2), fructose uptake (fup), the Entner-Doudoroff pathway (edp) and pyruvate carboxylase ( $p y c$; EC 6.4.1.1). Glucokinase was essential for glucose phosphorylation in $R$. trifolii and was also required for growth on sucrose. The $e d p$ mutant was impaired in growth on all hexoses tested except galactose, suggesting that the ED pathway was the major pathway used by $R$. trifolii for the catabolism of these sugars. Galactose may be catabolized via a different pathway, possibly involving an NADP ${ }^{+}$-linked galactose dehydrogenase. Pyruvate carboxylase was an important anaplerotic enzyme in $R$. trifolii required for growth on all carbon sources tested, except succinate.

All the mutants, including a $g l k$ fup double mutant, formed an effective symbiosis on red clover, suggesting that neither glucose, fructose nor sucrose are used by the bacteroids to provide ATP and reductant for nitrogen fixation. The bacteroids probably receive a supply of tricarboxylic acid cycle intermediates from the plant cytosol, and these may be their major source of energy.

\section{INTRODUCTION}

Carbohydrate supply is a major factor limiting nitrogen fixation by the Rhizobium-legume symbiosis (e.g. Bethlenfalvay \& Phillips, 1977; Hardy, 1977; Pate, 1977). Sucrose is the major product of photosynthesis translocated to the nodules (Bach et al., 1958) wherein its concentration has been related to the rate of acetylene reduction (nitrogen fixation) (Streeter \& Bosler, 1976). The nodule cytosol, however, contains an active invertase (Kidby, 1966, $1967)$ and little is known about the carbon source supplied to the bacteroids.

Succinate can support both $\mathrm{O}_{2}$-linked respiration (Tuzimura \& Meguro, 1960; Jordan, 1962) and nitrogen fixation (Bergersen \& Turner, 1967) in isolated bacteroids; but glucose (Tuzimura \& Meguro, 1960; Kidby, 1967) and sucrose (Bergersen \& Turner, 1967) were found to be ineffective in these roles, a result attributed to damage of a glucose transport mechanism during bacteroid preparation (Kidby, 1967). Rigaud et al. (1973) did find stimulation of acetylene reduction by glucose, and hexoses have been proposed to be the main substrates used by bacteroids in vivo (Bergersen, 1977).

Relatively little is known about the pathways of central carbohydrate metabolism in rhizobia. Both fast- and slow-growing species possess the Entner-Doudoroff pathway

* Present address: Grasslands Division, Department of Scientific and Industrial Research, Private Bag, Palmerston North, New Zealand. 
(Katznelson \& Zagallo, 1957; Keele et al., 1969; Martinez-de Drets \& Arias, 1972; Mulongoy \& Elkan, 1977a) but the existence of the Embden-Meyerhof-Parnas pathway in rhizobia is in doubt. Katznelson \& Zagallo (1957) reported fructose-1,6-bisphosphate aldolase and phosphofructokinase activities in fast-growing rhizobia, but Martinez-de Drets \& Arias (1972) were unable to find significant levels of fructose-1,6-bisphosphate aldolase in either fast- or slow-growing strains. However, Mulongoy \& Elkan (1977a) reported simultaneous operation of the Entner-Doudoroff and Embden-Meyerhof-Parnas pathways in $R$. japonicum and suggested that the efficiency of nitrogen fixation was correlated with the use of the latter pathway. Fast-growing rhizobia also possess NADP+-dependent 6-phosphogluconate dehydrogenase (Katznelson \& Zagallo, 1957), the key enzyme of the pentose phosphate pathway, but this has not been found in slow-growing rhizobia (Keele et al., 1969; Martinez-de Drets \& Arias, 1972; Mulongoy \& Elkan, $1977 a, b)$.

The tricarboxylic acid cycle also operates in hexose catabolism in $R$. japonicum (Keele et al., 1969; Mulongoy \& Elkan, 1977a) but the anaplerotic enzyme necessary for growth (Kornberg, 1966) has not been identified.

We have assayed some key enzymes of carbohydrate metabolism and isolated various mutants in carbohydrate metabolism to determine (i) the main pathway(s) of hexose catabolism used by a fast-growing species, $R$. trifolii, and (ii) the carbon source supplied to the bacteroids.

\section{METHODS}

Abbreviations. ED pathway, Entner-Doudoroff pathway; EMP pathway, Embden-Meyerhof-Parnas pathway; PP pathway, pentose phosphate pathway; 6PG, 6-phosphogluconate; KDPG, 2-keto-3-deoxy-6phosphogluconate.

Bacteria. Rhizobium trifolii NZP7 (designated strain 7000 in this work) was obtained from R. M. Greenwood, Applied Biochemistry Division, D.S.I.R., Palmerston North, New Zealand, and maintained at $-20{ }^{\circ} \mathrm{C}$ on glass beads in defined medium containing $20 \%$ (v/v) glycerol. Mutants derived from strain 7000 are described in Table 1.

Media. Defined medium (RDM) contained (g ${ }^{-1}$ in distilled water): $\mathrm{KH}_{2} \mathrm{PO}_{4}, 1 \cdot 0 ; \mathrm{K}_{2} \mathrm{HPO}_{4}, 1 \cdot 0 ; \mathrm{NH}_{4} \mathrm{Cl}$, $0.11 ; \mathrm{MgSO}_{4} .7 \mathrm{H}_{2} \mathrm{O}, 0.25 ; \mathrm{NaCl}, 0.2 ; \mathrm{CaCl}_{2} .2 \mathrm{H}_{2} \mathrm{O}, 0.02$. $\mathrm{RDM}$ was normally supplemented with trace elements and vitamins as described by Brown \& Dilworth (1975) except that biotin was added to $20 \mu \mathrm{g} \mathrm{l}^{-1}$. The phosphates were autoclaved separately. Vitamins and $\mathrm{NH}_{4} \mathrm{Cl}$ were omitted for $\mathrm{RDM}$ nitrogen-free salts medium. Carbon sources were either filter-sterilized (growth rate experiments) or autoclaved separately (other experiments) and were added to a final concentration of $0.4 \%(\mathrm{w} / \mathrm{v})$. Complex medium was glucose/ salts/yeast extract/casein acid hydrolysate medium (GSYC; Schwinghamer, 1960). RDM was solidified with Difco Noble agar, unless otherwise stated, and GSYC with Difco Bacto agar. Nutrient agar was prepared from dehydrated material (Oxoid).

Mutagenesis and isolation of mutant strains. Bacteria were grown to a density of approximately $10^{8} \mathrm{ml}^{-1}$ in the non-selective medium (Table 2) and then treated with $200 \mu \mathrm{g} N$-methyl- $N^{\prime}$-nitro- $N$-nitrosoguanidine $\mathrm{ml}^{-1}$. After $20 \mathrm{~min}$, bacteria were sedimented, washed twice in the medium used for mutagenesis, allowed to grow overnight in the same medium and then subjected to enrichment. For enrichment, the overnight culture was washed and diluted to $10^{5}$ to $10^{6}$ bacteria $\mathrm{ml}^{-1}$ in the selective medium (Table 2) and allowed to grow for $12 \mathrm{~h}$ before ampicillin $\left(25 \mu \mathrm{g} \mathrm{mi}^{-1}\right)$ was added. After a further $24 \mathrm{~h}$ the bacteria were washed, resuspended in the original non-selective medium and allowed to grow until the culture became turbid. This enrichment cycle was usually repeated (Table 2 ).

Enriched cultures were plated for single colonies on RDM (solidified with Difco Bacto agar) containing the selective carbon source, and after 4 to $16 \mathrm{~d}$ micro-colonies were picked on to suitable media for the identification of mutants.

Determination of growth. Single colonies were streaked on RDM plates containing the specified carbon source and (except for strain 7049) histidine. The amount of growth was recorded after incubation of the plates at $28^{\circ} \mathrm{C}$ for $5 \mathrm{~d}$. Doubling times were measured on cultures growing at $28^{\circ} \mathrm{C}$ with gentle shaking in $250 \mathrm{ml}$ Erlenmeyer flasks containing $50 \mathrm{ml}$ of the same medium without agar. The flasks were inoculated from streaked RDM plates containing inositol and histidine to give approximately $10^{7}$ bacteria $\mathrm{ml}^{-1}$. Growth was followed by measuring $A_{540}$ values in a Cecil CE202 spectrophotometer from $16 \mathrm{~h}$ after inoculation up to $96 \mathrm{~h}$, where necessary.

Preparation of bacterial extracts. One-litre flasks containing $500 \mathrm{ml} \mathrm{RDM}$ with the appropriate carbon 


\section{Table 1. Mutants derived from Rhizobium trifolii 7000}

\begin{tabular}{cll} 
Strain & \multicolumn{1}{c}{ Characteristics* } & \multicolumn{1}{c}{ Source } \\
7008 & trp-4 & NTG $\dagger$ mutagenesis of 7000 \\
7009 & trp-4 glk-4 & NTG mutagenesis of 7008 (this work) \\
7012 & his-6 & NTG mutagenesis of 7000 \\
7013 & his-6 glk-7 & NTG mutagenesis of 7012 (this work) \\
7014 & glk-4 & Trp ${ }^{+}$revertant of 7009 (this work) \\
7028 & his-6 edp-1 & NTG mutagenesis of 7012 (this work) \\
7039 & his- 6 glk-7 fup-1 & NTG mutagenesis of 7013 (this work) \\
7049 & pyc-2 & NTG mutagenesis of 7000 (this work)
\end{tabular}

* $e d p$, deficient in Entner-Doudoroff pathway; fup, deficient in fructose uptake; glk, deficient in glucokinase; his, requirement for histidine; $p y c$, deficient in pyruvate carboxylase; trp, requirement for tryptophan. $\dagger$ NTG, $N$-methyl- $N^{\prime}$-nitro- $N$-nitrosoguanidine.

\section{Table 2. Media and number of ampicillin enrichment cycles used to isolate mutant strains}

Carbon sources $(0 \cdot 4 \%, \mathrm{w} / \mathrm{v})$ and amino acids $\left(100 \mu \mathrm{g} \mathrm{ml}^{-1}\right)$ were added to $\mathrm{RDM}$ as stated.

$\begin{array}{cl}\text { Strain } & \text { Non-selective medium } \\ 7009 & \text { GSYC } \\ 7013 & \text { GSYC } \\ 7028 & \text { RDM + inositol + histidine } \\ 7039 & \text { RDM + inositol + histidine } \\ 7049 & \text { RDM + glucose + glutamine } \\ & \text { + glutamate }\end{array}$

Selective medium

RDM + glucose + tryptophan

RDM + glucose + histidine

$\mathrm{RDM}+$ fructose + histidine

$\mathrm{RDM}+$ fructose + histidine

$\mathrm{RDM}+$ glucose
No. of ampicillin enrichment cycles

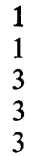

3

RDM, Defined medium; GSYC, glucose/salts/yeast extract/casein hydrolysate medium.

source(s) were inoculated from fresh plates to give approximately $10^{7}$ bacteria $\mathrm{ml}^{-1}$. Cultures were grown at $28{ }^{\circ} \mathrm{C}$ with shaking and, just before harvesting, were checked for contamination by streaking on nutrient agar and on RDM containing a selective carbon source. Rhizobium trifolii does not grow on nutrient agar, and the phenotype of the culture was checked on the RDM plates. Cultures were harvested while they were in the exponential phase of growth $\left(2 \times 10^{8}\right.$ to $5 \times 10^{8}$ bacteria $\left.\mathrm{ml}^{-1}\right)$, washed twice in $20 \mathrm{mM}-\mathrm{KH}_{2} \mathrm{PO}_{4} /$ $\mathrm{K}_{2} \mathrm{HPO}_{4}$ buffer ( $\mathrm{pH} 7 \cdot 6$ ) at room temperature, resuspended in cold $\left(4^{\circ} \mathrm{C}\right) 20 \mathrm{mM}-\mathrm{N}$-2-hydroxyethylpiperazine$N^{\prime}$-2-ethanesulphonate (HEPES) buffer (pH 7.6) containing 1 mM-dithioerythritol and passed once through a French pressure cell at $137 \mathrm{MPa}$. The extract was then centrifuged at $38000 \mathrm{~g}$ for $1 \mathrm{~h}$ at $4{ }^{\circ} \mathrm{C}$ and the supernatant fluid was used for assays. When NADPH-linked enzymes were to be assayed the period of centrifugation was extended to $2 \mathrm{~h}$. Protein was determined by the biuret method (Herbert et al., 1971) using crystalline bovine serum albumin as standard.

Enzyme assays. All enzyme assays were done at $28^{\circ} \mathrm{C}$ in 20 mM-HEPES buffer (pH 7.6) unless otherwise stated. Glucokinase [EC 2.7.1.2; ATP:D-glucose 6-phosphotransferase] was assayed according to Anderson \& Kamal (1966); fructokinase [EC 2.7.1.4; ATP:D-fructose 6-phosphotransferase] was assayed in a similar manner except that fructose replaced glucose in the assay mixture. Glucosephosphate isomerase [EC 5.3 1.9; D-glucose-6-phosphate ketol-isomerase] was assayed according to Noltman (1966), glucose-6-phosphate dehydrogenase [EC 1.1.1.49; D-glucose-6-phosphate:NADP ${ }^{+}$1-oxidoreductase] according to Kuby \& Noltman (1966) and 6-phosphogluconate (6PG) dehydrogenase [EC 1.1.1.44; 6-phospho-D-gluconate: $\mathrm{NADP}^{+}$2-oxidoreductase (decarboxylating)] as for glucose-6-phosphate dehydrogenase except that $6 \mathrm{PG}$ replaced glucose 6-phosphate. Fructose-bisphosphate aldolase [EC 4.1.2.13; fructose-1,6-bisphosphate D-glyceraldehyde-3-phosphate-lyase] was assayed by the method described for the yeast enzyme by Rutter et al. (1966) and phosphofructokinase [EC 2.7.11.1; ATP:D-fructose-6-phosphate 1-phosphotransferase] was assayed as described by Ling et al. (1966).

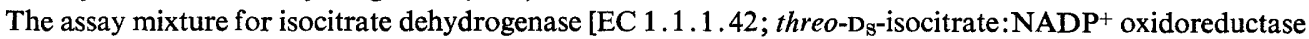
(decarboxylating)] contained $8 \mathrm{~mm}$-DL-isocitrate, $2 \mathrm{~mm}-\mathrm{MnSO}_{4}, 1 \mathrm{~mm}$-dithioerythritol and $1 \mathrm{~mm}-\mathrm{NADP}^{+}$. Malate dehydrogenase [EC 1.1 1.1.37; L-malate: $\mathrm{NAD}^{+}$oxidoreductase] was assayed at $\mathrm{pH} 10.0$ as described by Englard \& Siegel (1969). The assay mixture for galactose dehydrogenase contained 2 mM-galactose, $3 \mathrm{mM}-\mathrm{MgCl}_{2}$ and $1 \mathrm{mM}-\mathrm{NADP}{ }^{+}$. 
The ED pathway ('ED enzyme') was determined by following the production of pyruvate from 6PG. The reaction mixture contained $5 \mathrm{mM}-6 \mathrm{PG}, 4 \mathrm{mM}-\mathrm{MgCl}_{2}, 3 \mathrm{mM}$-dithioerythritol and extract (approximately $1 \mathrm{mg}$ protein) in a final volume of $1 \mathrm{ml}$. Assays were run at $30^{\circ} \mathrm{C}$ for the specified time (usually $10 \mathrm{~min}$ ) and the pyruvate formed was determined as described by Keele et al. (1969). No attempt was made to separate phosphogluconate dehydratase [EC 4.2.1.12; 6-phospho-D-gluconate hydro-lyase] and 2-keto-3-deoxy-6phosphogluconate (KDPG) aldolase [EC 4.1.2.14; 6-phospho-2-keto-3-deoxy-D-gluconate D-glyceraldehyde-3-phosphate-lyase] activities.

The pyruvate carboxylase [EC 6.4.1.1; pyruvate:carbon-dioxide ligase (ADP-forming)] assay was modified from that described by Phibbs et al. (1974). The reaction mixture contained $20 \mathrm{mM}-\mathrm{Tris} / \mathrm{HCl}$ (pH 7.8), $0.5 \mathrm{~mm}$-sodium pyruvate, $0.8 \mathrm{~mm}$-ATP, $4 \mathrm{~mm}-\mathrm{MgCl}_{2}, 0.034 \mathrm{~mm}$-acetyl-CoA, $0.63 \mathrm{~mm}$-NADH, 2 mM-dithioerythritol, $12.5 \mathrm{mM}-\mathrm{NaH}^{14}{ }^{14} \mathrm{C}_{3} \mathrm{O}_{3}\left(1.6 \mu \mathrm{Ci} \mu \mathrm{mol}^{-1}\right)$ and $200 \mu \mathrm{l}$ extract in a final volume of $0.5 \mathrm{ml}$. The extracts contained high concentrations of malate dehydrogenase so no exogenous malate dehydrogenase was added. The mixtures were incubated for $10 \mathrm{~min}$ and then the reactions were started by adding pyruvate. For avidin treatment, $50 \mu \mathrm{g}$ avidin were added to each reaction mixture before pre-incubation. After $10 \mathrm{~min}$, the reactions were stopped by adding $200 \mu \mathrm{l}$ of $12 \mathrm{M}$-formic acid, and $200 \mu \mathrm{l}$ of the mixture were then transferred to a scintillation vial and dried at $80^{\circ} \mathrm{C}$ for at least $3 \mathrm{~h}$. The residue was suspended in $1 \mathrm{ml} \mathrm{H}_{2} \mathrm{O}, 10 \mathrm{ml}$ of scintillation fluid were added and the radioactivity was determined. The counting efficiency was calculated to be $63 \%$.

Uptake of radioactive sugars. Bacteria grown in RDM with the appropriate carbon source were harvested during the exponential growth phase $\left(10^{8}\right.$ to $5 \times 10^{8}$ bacteria $\left.\mathrm{ml}^{-1}\right)$, washed once at room temperature with RDM nitrogen-free salts medium, resuspended in the same medium to an $A_{540}$ of $1.00\left(10^{9}\right.$ bacteria $\left.\mathrm{ml}^{-1}\right)$ and used immediately. A sample $(1.8 \mathrm{ml})$ of this suspension was shaken at $28^{\circ} \mathrm{C}$ in a $25 \mathrm{ml}$ Erlenmeyer flask for $10 \mathrm{~min}$ before adding $0.2 \mathrm{ml}{ }^{14} \mathrm{C}$-labelled sugar to give $1 \mathrm{mM}\left(1.25 \mu \mathrm{Ci} \mu \mathrm{mol}^{-1}\right)$. Samples were taken rapidly at specified intervals, filtered with suction through Millipore filters $(0.45 \mu \mathrm{m}$ pore size $)$ and washed twice with $2 \mathrm{ml}$ of RDM nitrogen-free salts medium. Filters were transferred to scintillation vials, dried and counted in $10 \mathrm{ml}$ of scintillation fluid.

Measurement of radioactivity. This was done in a Packard Tri-carb liquid scintillation spectrometer. The scintillation fluid had the following composition: toluene, 11 ; Triton X-100, 0.5 1; 2,5-diphenyloxazole, $6.0 \mathrm{~g}$; 1,4-di-2-(5-phenyloxazolyl)benzene, $75 \mathrm{mg}$.

Nodulation tests. Gibson's partly enclosed seedling method and Jensen's seedling solution were used (Vincent, 1970). The test cultivar was red clover (Trifolium pratense) var. Atteswede. All operations were done in a laminar flow hood, uninoculated controls were included and strain identity was confirmed from nodule crushes. Plants were grown in a plant growth room at $20^{\circ} \mathrm{C}$ under 10 klux and an $8.5 \mathrm{~h} \mathrm{light} / 15.5 \mathrm{~h}$ dark regime.

Nitrogen fixation was estimated by the acetylene reduction method (Bergersen, 1970). Entire root systems were cut off test plants and transferred to McCartney bottles containing $0.5 \mathrm{ml} \mathrm{H}_{2} \mathrm{O}$. The bottles were capped with rubber septa ('SubaSeal'; Freeman \& Co., Barnsley, Yorks.) and placed in a water bath at $25^{\circ} \mathrm{C}$. Air $(3.0 \mathrm{ml})$ was removed and $2.5 \mathrm{ml}$ acetylene added. Gas samples $(0.4 \mathrm{ml})$ were withdrawn after $5 \mathrm{~min}$ and $35 \mathrm{~min}$ and analysed using a Pye Unicam Series 104 chromatograph with a flame ionization detector, a $1.6 \mathrm{~m} \times 6 \mathrm{~mm}$ column of Porapak $\mathrm{R}$ at $60^{\circ} \mathrm{C}$ and a nitrogen carrier gas flow of $40 \mathrm{ml} \mathrm{min}{ }^{-1}$.

Seeds and nodules were surface-sterilized by immersion in ethanol for $30 \mathrm{~s}$ followed by $3 \mathrm{~min}$ in $0.2 \%$ acidified $\mathrm{HgCl}_{2}$ and six washes in sterile distilled water.

Chemicals. Biochemicals and enzymes were the highest grade available and were mainly from Sigma. Radioisotopic material was purchased from The Radiochemical Centre, Amersham.

\section{RESULTS}

\section{Enzymological studies on wild-type strain 7000}

The activities of a number of enzymes involved in carbohydrate metabolism were measured in crude extracts prepared from strain 7000 grown with glucose as sole carbon source (Table 3). Similar values were obtained when glycerol was the sole carbon source, indicating that none of the enzymes were induced specifically by hexoses. Growth on fructose resulted in an increased activity of fructokinase $\left[196 \mathrm{nmol} \mathrm{min}^{-1}(\mathrm{mg} \text { protein })^{-1}\right]$ but other enzyme activities remained the same.

In no case were we able to demonstrate phosphofructokinase activity in cell-free extracts and this, coupled with the low specific activity of fructose-bisphosphate aldolase, indicated that the EMP pathway was unlikedly to be physiologically significant in $R$. trifolii 7000 . 
Table 3. Activities of some enzymes of carbohydrate metabolism in R. trifolii strain 7000

Bacteria were grown in RDM containing $0.4 \%(w / v)$ glucose. Extracts were prepared and assayed as described in Methods.

$\begin{array}{lc}\text { Enzyme } & \begin{array}{c}\text { Activity [nmol } \text { min }^{-1} \\ \left.(\mathrm{mg} \mathrm{protein})^{-1}\right]\end{array} \\ \text { Glucokinase } & 178 \\ \text { Fructokinase } & 107 \\ \text { Glucosephosphate isomerase } & 1200 \\ \text { Glucose-6-phosphate dehydrogenase } & 214 \\ \text { 6-Phosphogluconate dehydrogenase } & 116 \\ \text { Fructose-bisphosphate aldolase } & 10 \\ \text { Phosphofructokinase } & 0 \\ \text { Galactose dehydrogenase } & 190 \\ \text { 'ED enzyme'* } & 108 \\ \text { Pyruvate carboxylase } & 8 \cdot 4 \\ \text { Isocitrate dehydrogenase } & 885 \\ \text { Malate dehydrogenase } & 920\end{array}$

* 'ED enzyme' represents the activity of the Entner-Doudoroff pathway as measured by the production of pyruvate from 6-phosphogluconate.

Of course, failure to detect phosphofructokinase activity does not rule out its existence. For example, we were unable to assay the particulate fraction of cell-free extracts for phosphofructokinase, and other enzymes whose assay was based on NADH oxidation, because of the high level of NADH oxidase activity in this fraction.

The operation of the ED pathway was shown by the production of pyruvate from 6PG in the absence of NADP + . Maximum production of pyruvate by extracts of strain 7000 under our conditions occurred within $30 \mathrm{~min}$ giving a specific activity of $108 \mathrm{nmol} \mathrm{min}-1$ (mg protein) $)^{-1}$, approximately four times the activity of 'ED enzyme' found in $R$. trifolii by Martinez-de Drets \& Arias (1972). These workers, however, ran their assay for $1 \mathrm{~h}$ and thus may have seriously underestimated the specific activity. A maximum of $3 \mu \mathrm{mol}$ pyruvate was accumulated under our conditions from the $5 \mu \mathrm{mol} 6 \mathrm{PG}$ initially present and the addition of sodium arsenite $(6 \mu \mathrm{mol})$, which inhibits the oxidative decarboxylation of pyruvate, had no effect on this activity.

A high activity of 6PG dehydrogenase, the key enzyme of the PP pathway, was also found, as were various enzymes of the tricarboxylic acid cycle, indicating the potential for these pathways to operate in $R$. trifolii.

An NADP+-linked galactose dehydrogenase was also found. The activity of this enzyme was the same irrespective of the carbon source provided.

\section{Isolation and growth properties of mutant strains}

The procedure used to isolate strains 7009 and 7013 (Table 2) was originally designed to yield amino-acid auxotrophs. However, the enriched cultures in GSYC took $6 \mathrm{~d}$ to become turbid and approximately $50 \%$ of the population displayed a glucose-negative phenotype. This result was particularly surprising since glucose was the major carbon source in the GSYC medium used for growth following ampicillin enrichment. Strains 7028 and 7039 were isolated on the basis of their fructose-negative phenotype and were the only fructosenegative mutants found. Strain 7049 was one of many succinate-dependent mutants found in six independent experiments.

The growth of these mutant strains on some carbon sources is shown in Table 4, which also includes doubling times where these were determined. Strain 7014 (a Trp ${ }^{+}$revertant of strain 7009, see Table 1) was used for these experiments instead of strain 7009 because strain 7008 (the Trp- parent of strain 7009) had a slower doubling rate than strains 7000 and 7012 on all media. Neither wild-type nor mutant strains were able to grow on glucose 6-phosphate, 
Table 4. Growth of mutant strains on different carbon sources

Growth was determined as described in Methods. Doubling times (h), shown in parentheses, are the averages of two determinations.

\begin{tabular}{|c|c|c|c|c|c|}
\hline \multirow[b]{2}{*}{ Carbon source } & \\
\hline & 7012 & 7014 & 7039 & 7028 & 7049 \\
\hline Glucose & $+t+(3.5)$ & $-(>50 \cdot 0)$ & - & $-\quad(>50 \cdot 0)$ & - \\
\hline Fructose & $+t+(3.6)$ & +++ & $-(16.0)$ & $(14 \cdot 0)$ & - \\
\hline Sucrose & $+++(4 \cdot 0)$ & $-(27 \cdot 2)$ & - & $(7 \cdot 6)$ & - \\
\hline Sorbitol & $+++(3.4)$ & +++ & $++t$ & $(9 \cdot 2)$ & - \\
\hline Mannitol & $+++(3 \cdot 5)$ & +++ & +++ & $+\quad(10 \cdot 0)$ & - \\
\hline Galactose & $+++(3.4)$ & +++ & +++ & $+++(3 \cdot 5)$ & - \\
\hline Lactose & +++ & - & - & $+t+$ & - \\
\hline Ribose & +++ & $+t+$ & +++ & $+t+$ & - \\
\hline Glycerol & +++ & +++ & +++ & $++t$ & - \\
\hline \multicolumn{6}{|l|}{ Glucose + } \\
\hline $1 \mathrm{~mm}$-succinate & +++ & - & - & - & $++t$ \\
\hline Succinate & +++ & $++t$ & +++ & ++ & +++ \\
\hline
\end{tabular}

$*+++$, Growth as good as wild-type; + , poor growth compared with wild-type; - , no growth.

sodium gluconate or sodium glucuronate. Growth on succinate was obtained only on solid media.

\section{Characterization of strains 7009 and 7013}

Strains 7009 and 7013, originally found to be glucose-negative, lacked only glucokinase (genotype $g l k$ ) of the enzymes of hexose metabolism listed in Table 3. Both mutants had impaired growth on sucrose, lactose, maltose, trehalose and dulcitol, but grew normally on glucose plus fructose or glucose plus galactose. Strain 7009 could take up glucose at a similar initial rate to wild-type cells (Fig. 1). Results for bacteria grown in the absence of glucose were similar indicating that glucose transport is constitutive in both wild-type and mutant strains. Revertants of strain 7009 isolated on glucose arose at a frequency of $10^{-6}$ to $10^{-7}$ and had regained the ability to grow on all carbon sources. Four revertants tested had regained normal glucokinase activity. Further details of these mutants will be published elsewhere.

\section{Characterization of strain 7039}

Strain 7039 contained all the hexose-catabolizing enzymes listed in Table 3, except glucokinase. It was, however, defective in fructose uptake (genotype fup) (Fig. 2). The uptake of glucose was unaffected (Fig. 1).

Strain 7039 grew very slowly on fructose (Table 4), presumably by taking up fructose by passive diffusion, and so fructose-positive revertants were selected by serial culture in RDM plus fructose. Twenty independent revertants were isolated and all had regained the ability to take up fructose. Seven of the 20 revertants were also able to take up fructose after growth in the absence of fructose, i.e. were constitutive for fructose uptake. Thi s suggests that the original mutation was in a regulatory rather than a structural gene.

\section{Characterization of strain 7028}

Strain 7028, isolated as fructose-negative, was also impaired in growth on sucrose, glucose, mannose, mannitol and sorbitol (Table 4). Its growth rate on solid media containing lactose, galactose, arabinose, ribose, glycerol, arabitol, ribitol or inositol as carbon source was similar to that of its parent strain, 7012. Growth on glucose plus galactose was also normal. Uptake of glucose, fructose and mannitol by induced cultures was also at wild-type rates. Revertants (frequency $10^{-7}$ to $10^{-8}$ ) isolated on glucose, fructose or sorbitol had regained the ability to grow on all of the carbon sources.

Strain 7028 contained all the enzymes listed in Table 3 except 'ED enzyme'. In particular, 


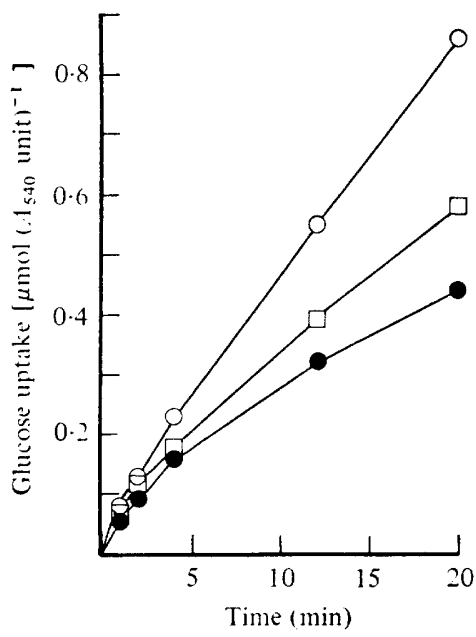

Fig. 1

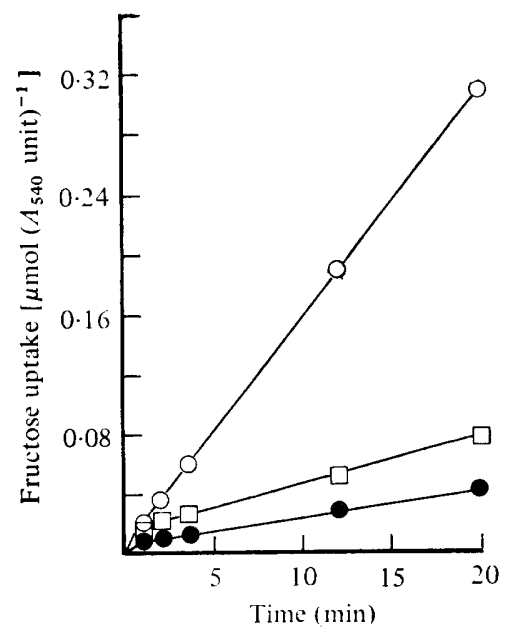

Fig. 2

Fig. 1. Uptake of glucose by strains 7000,7009 and 7039. Bacteria were grown in RDM containing $100 \mu \mathrm{g}$ histidine $\mathrm{ml}^{-1}, 100 \mu \mathrm{g}$ tryptophan $\mathrm{ml}^{-1}, 0.4 \%(\mathrm{w} / \mathrm{v})$ glucose and $0.4 \%(\mathrm{w} / \mathrm{v})$ inositol, and were harvested and assayed for glucose uptake as described in Methods: $\bigcirc$, strain 7000; $\square$, strain 7009 ;, strain 7039.

Fig. 2. Uptake of $\left[{ }^{14} \mathrm{C}\right]$ fructose by strains 7013 and 7039. Bacteria were grown in RDM containing $100 \mu \mathrm{g}$ histidine $\mathrm{ml}^{-1}$ and the specified carbon source(s) (each at $0.4 \%, \mathrm{w} / \mathrm{v}$ ) and were assayed for fructose uptake as described in Methods: $\bigcirc$, strain 7013 grown with fructose plus inositol; strain 7039 grown with fructose plus inositol; $\square$, strain 7013 grown with inositol.

it contained wild-type amounts of glucose-6-phosphate dehydrogenase and 6PG dehydrogenase and its ability to grow normally on ribose and other pentoses and pentitols indicated that the strain possessed an intact PP pathway.

\section{Characterization of strain 7049}

Strain 7049 was unable to grow on any hexose, pentose or triose tested but retained the ability to grow on succinate (Table 4). It was able to grow on RDM containing glucose if the medium was supplemented with succinate, malate, glutamine, glutamate, histidine or proline at $50 \mu \mathrm{g} \mathrm{ml}^{-1}$. Supplementation with the other common amino acids or pyruvate or acetate had no effect. Growth of both strain 7000 and the mutant strain was inhibited by 2-oxoglutarate, and citrate was toxic. Single-step revertants isolated on glucose (frequency $10^{-8}$ ) had regained the wild-type growth patterns. These properties, shared by the other succinate-dependent mutants isolated, strongly suggested that the mutant lacked an anaplerotic enzyme.

Strain 7000 showed pyruvate carboxylase activity which was stimulated approximately fourfold by acetyl-CoA, a property shared by many pyruvate carboxylases (Utter \& Scrutton, 1969). The activity was abolished by treatment of the extract with avidin, an inhibitor specific for biotin-containing enzymes such as pyruvate carboxylase (Utter \& Scrutton, 1969). Strain 7049 lacked pyruvate carboxylase activity (Table 5) and a revertant of strain 7049 had regained pyruvate carboxylase activity identical to strain 7000 .

Apparent phosphoenolpyruvate carboxylase and carboxykinase activities were also found but these were stimulated by acetyl-CoA and were susceptible to avidin. They were therefore dependent on pyruvate carboxylase whose substrate (pyruvate) is generated from phosphoenolpyruvate by the action of pyruvate kinase. Furthermore, in strain 7049 both activities were lost, and in revertants both activities were restored along with pyruvate carboxylase. 
Table 5. Incorporation of $\mathrm{H}^{14} \mathrm{CO}_{3}$ by extracts of strain 7000 and strain 7049

Bacteria were grown in RDM containing $0.4 \%(\mathrm{w} / \mathrm{v})$ glucose and $1 \mathrm{~mm}$-succinate. Extracts were prepared and assayed as described in Methods. Activities are expressed as d.p.m. min $^{-1}\left(\mathrm{mg}^{2}\right.$ protein) $)^{-1}$.

\begin{tabular}{lrc} 
& \multicolumn{2}{c}{$\begin{array}{c}\text { Pyruvate carboxylase activity } \\
\text { in strain: }\end{array}$} \\
Reaction mixture & 7000 & 7049 \\
- Pyruvate & 226 & 156 \\
- ATP & 547 & 142 \\
- Acetyl-CoA & 1195 & 129 \\
Complete & 4897 & 113 \\
Complete; avidin-treated & 126 & ND \\
& ND, Not done. &
\end{tabular}

\section{Symbiotic properties of mutant strains}

Nodulation tests were done using Gibson's partly enclosed seedling method which allows the time of onset of nodulation as well as effectiveness to be monitored. Strain 7014 was used in place of strain 7009 for nodulation tests because strain 7008 forms a defective symbiosis as a consequence of its requirement for tryptophan (unpublished observation). No significant difference in the time of onset of nodulation, colour of nodules, plant response or acetylene reduction levels was noted for any of the strains tested. Acetylene reduction values per root estimated $30 \mathrm{~d}$ after inoculation were in the range of 7 to $10 \mathrm{nmol} \mathrm{h}^{-1}$.

Six nodules formed by each strain (one nodule per test plant) were surface-sterilized, crushed and streaked on various media to determine their phenotype. In each case, rhizobia recovered from the nodule had the same phenotype as the strain used for inoculation.

\section{DISCUSSION}

Rhizobium trifolii strain 7000 contained key enzyme activities of the ED and PP pathways (see Fig. 3). The lack of phosphofructokinase indicates that the EMP pathway was absent. This is contrary to a previous report (Katznelson \& Zagallo, 1957) but agrees with Martinezde Drets \& Arias (1972). The latter authors, like us, were unable to demonstrate significant levels of fructose-bisphosphate aldolase in most of their strains though they did not assay for phosphofructokinase.

The properties of strains 7009 and 7013 indicated that the wild-type strain was wholly dependent on glucokinase for growth on glucose. The glucokinase-negative mutant strains were able to take up glucose at similar rates to the wild-type strain (Fig. 1); thus $R$. trifolii, in common with other obligately aerobic bacteria (Romano et al., 1970), does not appear to contain a PEP:hexose phosphotransferase system. Sucrose metabolism was also impaired in strain 7009; this was a consequence of the glucokinase mutation because all revertants isolated on glucose had regained the ability to grow on sucrose. The basis for the slow growth on sucrose was not examined but must presumably be at the level of either sucrose uptake or splitting because the mutant was able to grow normally on a mixture of glucose plus fructose.

Strain 7028, deficient in either 6-phosphogluconate dehydratase or KDPG aldolase, had lost the ability to grow on glucose and was severely impaired in its ability to grow on other hexoses except galactose. This provides further evidence that the ED pathway plays a major role in hexose metabolism. The mutant grew very slowly on sucrose and on hexoses except glucose, presumably via the PP pathway, of which the key enzyme, NADP ${ }^{+}$-dependent $6 \mathrm{PG}$ dehydrogenase, was present at high specific activity. Indeed, the activity of NADP ${ }^{+}-6 \mathrm{PG}$ dehydrogenase was such that no impairment of growth might be expected. However, a 


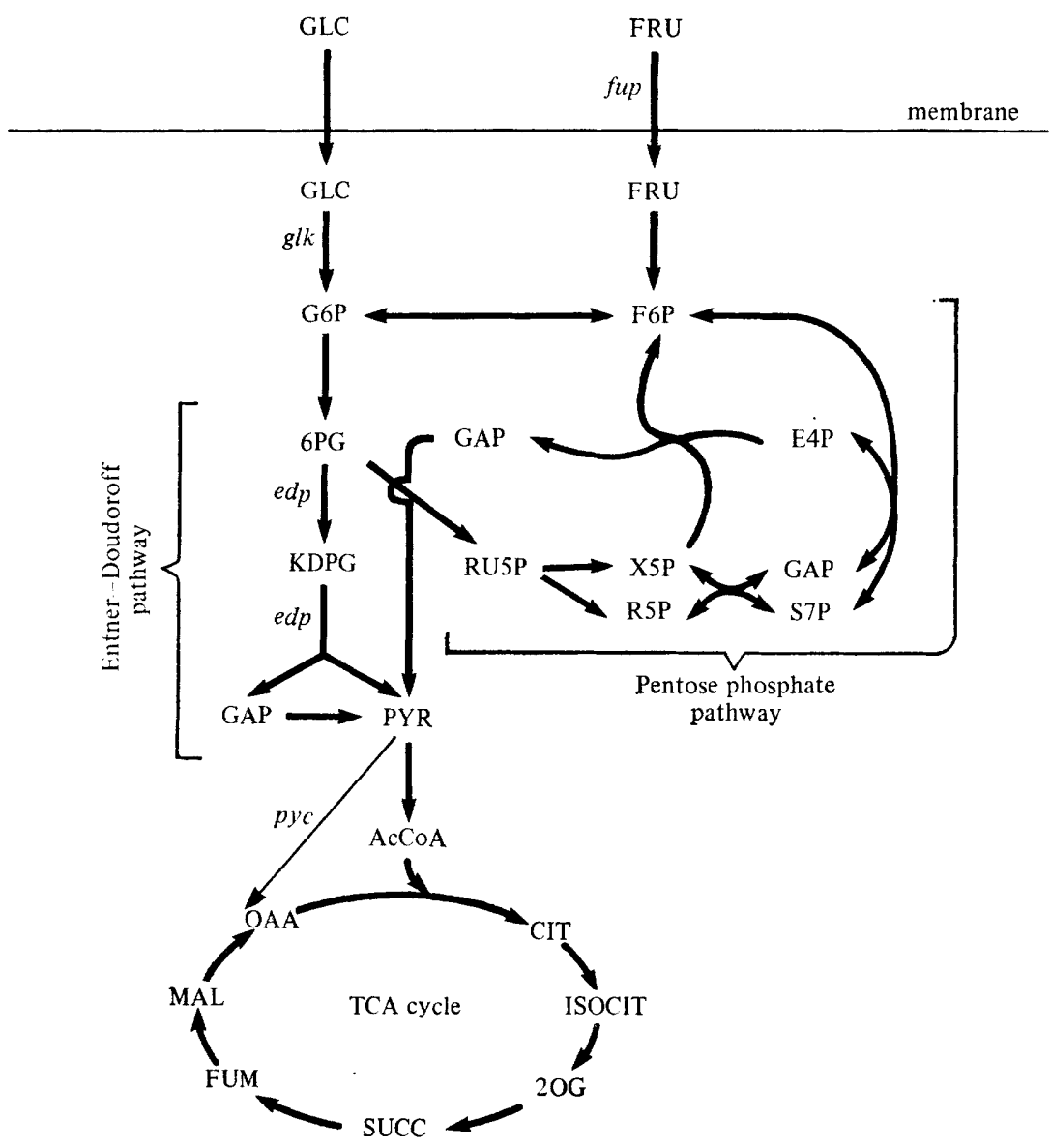

Fig. 3. Pathways of glucose and fructose catabolism available to $R$. trifolii strain 7000 . The mutants are blocked at the steps indicated: $g l k$, strains 7009, 7013 and 7039 ; fup, strain 7039; pyc, strain 7049. Strain 7028 is blocked at one of the two steps labelled $e d p$.

Abbreviations: GLC, glucose; FRU, fructose; G6P, glucose 6-phosphate; F6P, fructose 6phosphate; 6PG, 6-phosphogluconate; KDPG, 2-keto-3-deoxy-6-phosphogluconate; GAP, glyceraldehyde 3-phosphate; RU5P, ribulose 5-phosphate; X5P, xylulose 5-phosphate; R5P, ribose 5-phosphate; S7P, sedoheptulose 7-phosphate; E4P, erythrose 4-phosphate; PYR, pyruvate; AcCoA, acetyl-CoA; OAA, oxaloacetate; CIT, citrate; ISOCIT, isocitrate; 2OG, 2-oxoglutarate; SUCC, succinate; FUM, fumarate; MAL, malate; TCA, tricarboxylic acid.

functional ED pathway may be necessary for growth for a number of reasons. In Escherichia coli, KDPG accumulated by KDPG aldolase-negative mutants is inhibitory and thereby inhibits growth on gluconate despite the availability of the PP pathway (Fradkin \& Fraenkel, 1971). However, strain 7028 grew normally on glucose plus galactose and on lactose, indicating that an inhibitory compound was not accumulated in this strain.

Sole use of the PP pathway may be too inefficient to support growth, with only $1 \mathrm{~mol}$ acetyl-CoA produced per mol glucose, or it may lead to other metabolic imbalances. For example, an excess of NADPH may be generated and may lead to a shortage of NADP+ which is required as co-factor for glucose-6-phosphate dehydrogenase, 6PG dehydrogenase, glyceraldehyde-3-phosphate dehydrogenase and isocitrate dehydrogenase in $R$. trifolii (Table 3). A similar explanation has been proposed for the inability of glucosephosphate isomerase-negative mutants of $E$. coli to grow on glucose despite the availability of the PP pathway (Fraenkel \& Vinopal, 1973). Nevertheless, strain 7028 did not grow equally well 
on all carbon sources whose catabolism should be equally impaired (Table 4), and further investigation of this point is required.

Mutants in the ED pathway unable to grow on glucose have been described in Pseudomonas aeruginosa (Blevins et al., 1975) and Pseudomonas putida (Vicente \& Canovas, 1973), both of which lack the EMP pathway. However, $P$. aeruginosa did not contain 6PG dehydrogenase (Blevins et al., 1975) and no evidence for the PP pathway in P. putida was presented (Vicente \& Canovas, 1973).

The normal growth of strain 7028 on lactose and on galactose suggested that $R$. trifolii catabolized galactose by a different pathway. We have identified an NADP+-linked galactose dehydrogenase which may initiate a pathway similar to that initiated by the $\mathrm{NAD}^{+}$-linked galactose dehydrogenase (EC 1.1.1.48) in Pseudomonas saccharophila (De Ley \& Doudoroff, 1957).

The effective symbiotic properties of strains 7013 and 7014 indicate that glucose is not catabolized by the bacteroids to provide the ATP and reductant for nitrogen fixation. Strain 7039 was isolated from strain 7013 and was defective in the uptake of fructose, the other product of invertase. The effectiveness of this strain strongly suggests that neither sucrose, glucose nor fructose are used by the bacteroids, although the bacteroids might take up fructose and/or glucose by different mechanisms, perhaps involving phosphorylation. However, the effective symbiotic properties of strain 7028 provide further evidence that glucose or fructose catabolism by the bacteroid is not necessary for an effective symbiosis to be formed and also suggest that metabolites of glucose such as glucose 6-phosphate are not provided to the bacteroids by the plant.

The properties of strain 7049 showed that pyruvate carboxylase is required for growth on hexoses, pentoses and trioses in $R$. trifolii, as it is in the closely related Agrobacterium tumefaciens (Chern et al., 1976) and in P. aeruginosa (Phibbs et al., 1974). The anaplerotic enzyme is required to replace tricarboxylic acid cycle intermediates used in amino acid and haem biosynthesis (Kornberg, 1966). The symbiotic properties of histidine-negative (this paper) and glutamate-negative mutants (Kondorosi et al., 1977) show that the nodule cytosol provides adequate levels of amino acids normally synthesized from the intermediates. However, bacteroids are very active in haem biosynthesis (Cutting \& Schulman, 1969; Godfrey et al., 1975; Nadler \& Avissar, 1977). Hence the effective symbiotic properties of the pyruvate carboxylase-negative mutants suggest that the bacteroids receive a supply of tricarboxylic acid cycle intermediates from the nodule cytosol. These may therefore be the major energy source received by the bacteroids and used to provide the ATP and reductant required for nitrogen fixation. This suggestion is supported by the observation that succinate was the most effective substrate for enhancing nitrogen fixation by bacteroids in vitro (Bergersen \& Turner, 1967).

C.W.R. is grateful to the National Research Advisory Council, New Zealand, for a Fellowship and to Grasslands Division, D.S.I.R., Palmerston North, New Zealand, for leave of absence.

\section{REFERENCES}

ANDERson, R. L. \& Kamal, M. Y. (1966). Glucokinase. II. Aerobacter aerogenes. Methods in Enzymology 9, 388-392.

BACH, M. K., MAGeE, W. E. \& Burris, R. H. (1958). Translocation of photosynthetic products to soybean nodules and their role in nitrogen fixation. Plant Physiology 33, 118-124.

Bergersen, F. J. (1970). The quantitative relationship between nitrogen fixation and the acetylenereduction assay. Australian Journal of Biological Sciences 23, 1015-1025.
Bergersen, F. J. (1977). Physiological chemistry of dinitrogen fixation by legumes. In $A$ Treatise on Dinitrogen Fixation. Section III: Biology, pp. 519-556. Edited by R. W. F. Hardy \& W.S. Silver. New York: Wiley-Interscience.

Bergersen, F. J. \& TuRnER, G. L. (1967). Nitrogen fixation by the bacteroid fraction of breis of soybean root nodules. Biochimica et biophysica acta 141, 507-515.

Bethlenfalvay, G. J. \& Phillips, D. A. (1977). Photosynthesis and symbiotic nitrogen fixation in 
Phaseolus vulgaris L. In Genetic Engineering for Nitrogen Fixation, pp. 401-408. Edited by A. Hollaender. New York \& London: Plenum Press.

Blevins, W. T., Feary, T. W. \& Phibbs, P. V. (1975). 6-Phosphogluconate dehydratase deficiency in pleiotropic carbohydrate-negative mutant strains of Pseudomonas aeruginosa. Journal of Bacterio$\log y$ 121, 942-949.

Brown, C. M. \& Dilworth, M. J. (1975). Ammonia assimilation by Rhizobium cultures and bacteroids. Journal of General Microbiology 86, $39-48$.

Chern, C., Kusaka, I. \& Fukui, S. (1976). Significance of pyruvate carboxylase in sugar metabolism of Agrobacterium tumefaciens. Agricultural and Biological Chemistry 40, 771-778.

Cutting, J. A. \& Schulman, H. M. (1969). The site of haem synthesis in soybean nodules. Biochimica et biophysica acta 192, 486-493.

De LeY, J. \& DoudorofF, M. (1957). The metabolism of D-galactose in Pseudomonas saccharophila. Journal of Biological Chemistry 227, 745757.

ENGLARD, S. \& Siegel, L. (1969). Mitochondrial L-malate dehydrogenase of beef heart. Methods in Enzymology 13, 99-106.

Fradkin, J. E. \& Fraenkel, D. G. (1971). 2-Keto3-deoxygluconate 6-phosphate aldolase mutants of Escherichia coli. Journal of Bacteriology 108, $1277-1283$

Fraenkel, D. G. \& Vinopal, R. T. (1973). Carbohydrate metabolism in bacteria. Annual Review of Microbiology 27, 69-100.

Godfrey, C. A., Coventry, D. R. \& Dilworth, M. J. (1975). Some aspects of leghaemoglobin biosynthesis. In Nitrogen Fixation by Free-living Micro-organisms, pp. 311-332. Edited by W. D. P. Stewart. Cambridge: Cambridge University Press.

HaRDY, R. W. F. (1977). Rate-limiting steps in biological photoproductivity. In Genetic Engineering for Nitrogen Fixation, pp. 369-397. Edited by A. Hollaender. New York \& London: Plenum Press.

Herbert, D., Phipps, D. J. \& Strange, R. E. (1971). Chemical analysis of microbial cells. Methods in Microbiology 5B, 209-344.

JORDAN, D. C. (1962). The bacteroids of the genus Rhizobium. Bacteriological Reviews 26, 119-141.

Katznelson, H. \& Zagallo, A. C. (1957). Metabolism of rhizobia in relation to effectiveness. Canadian Journal of Microbiology 3, 879-884.

Keele, B. B., Hamilton, P. B. \& Elkan, G. H. (1969). Glucose catabolism in Rhizobium japonicum. Journal of Bacteriology 97, 1184-1191.

KIDBY, D. K. (1966). Activation of a plant invertase by inorganic phosphate. Plant Physiology 41, 1139-1144.

KIDBY, D. K. (1967). Carbon metabolism in legume root nodules. Ph.D. thesis, University of Western Australia.

Kondorosi, A., Svab, Z., Kiss, G. B. \& Dixon, R. A. (1977). Ammonia assimilation and nitrogen fixation in Rhizobium meliloti. Molecular and General Genetics 151, 221-226.

KorNBERG, H. L. (1966). Anaplerotic sequences and their role in metabolism. Essays in Biochemistry, 2 $1-31$.

KubY, S. A. \& Noltman, E. A. (1966). Glucose 6-phosphate dehydrogenase (crystalline) from Brewers' yeast. Methods in Enzymology 9, 116-125.

Ling, K. H., Paetkau, V., Marcus, F. \& Lardy, H. A. (1966). Phosphofructokinase. I. Skeletal muscle. Methods in Enzymology 9, 425-429.

Martinez-de Drets, G. \& ARias, A. (1972). Enzymatic basis for differentiation of Rhizobium into fast- and slow-growing groups. Journal of Bacteriology 109, 467-470.

Mulongoy, K. \& Elkan, G. H. (1977a). Glucose catabolism in two derivatives of a Rhizobium japonicum strain differing in nitrogen-fixing efficiency. Journal of Bacteriology 131, 179-187.

Mulongoy, K. \& ElKan, G. H. (1977b). The role of 6-phosphogluconate dehydrogenase in Rhizobium. Canadian Journal of Microbiology 23, 12931298.

NaDler, K. D. \& Avissar, Y. J. (1977). Heme synthesis in soybean root nodules. I. On the role of bacteroid $\delta$-aminolevulinic acid synthase and $\delta$-aminolevulinic acid dehydrase in the synthesis of the heme of leghemoglobin. Plant Physiology 60, 433-436.

Noltman, E. A. (1966). Phosphoglucose isomerase. I. Rabbit muscle (crystalline). Methods in Enzymo$\log y$ 9, 557-568.

PATE, J. S. (1977). Functional biology of dinitrogen fixation by legumes. In $A$ Treatise on Dinitrogen Fixation. Section III: Biology, pp. 473-518. Edited by R. W. F. Hardy \& W. S. Silver. New York: Wiley-Interscience.

Phibbs, P. V., Feary, T. W. \& Blevins, W. T. (1974). Pyruvate carboxylase deficiency in pleiotropic carbohydrate-negative mutant strains of Pseudomonas aeruginosa. Journal of Bacteriology 118, 999-1009.

Rigaud, J., Bergersen, F. J., Turner, G. L. \& DANIEL, R. M. (1973). Nitrate dependent anaerobic acetylene-reduction and nitrogen-fixation by soybean bacteroids. Journal of General Microbiology 77, 137-144.

Romano, A. H., Eberhard, S. J., Dingle, S. L. \& MCDowell, S. D. (1970). Distribution of the phosphoenolpyruvate:glucose phosphotransferase system in bacteria. Journal of Bacteriology 104, 803-813.

Rutter, W. J., Hunsley, J. R., Groves, W. E., Calder, J., Rajkumar, T. V. \& Woodfin, B. M. (1966). Fructose diphosphate aldolase. Methods in Enzymology 9, 479-498.

Schwinghamer, E. A. (1960). Studies on induced variation in the rhizobia. I. Defined media and nodulation test techniques. Applied Microbiology 8, 349-352.

Streeter, J. G. \& Bosler, M. E. (1976). Carbohydrates in soybean nodules: identification of compounds and possible relationships to nitrogen fixation. Plant Science Letters 7, 321-329.

Tuzimura, K. \& Meguro, H. (1960). Respiration substrate of Rhizobium in the nodules. Journal of Biochemistry 47, 391-397.

Utter, M. F. \& Scrutton, M. C. (1969). Pyruvate carboxylase. Current Topics in Cellular Regulation 1, 253-296. 

VICENTE, M. \& CANOVAS, J. L. (1973). Glucolysis in
Pseudomonas putida: physiological role of alter-

VinCENT, J. M. (1970). A Manual for the Practical native routes from the analysis of defective mutants. Journal of Bacteriology 116, 908-914.

Study of Root-nodule Bacteria, International Biological Programme Handbook No. 15. Oxford: Blackwell Scientific Publications. 